\title{
LA TRADUCCIÓN DE LA FÁBULA DE IFIS Y ANAXÁRETE: A PROPÓSITO DE LA CONFESSIO AMANTIS DE JOHN GOWER Y SUS TRADUCTORES PENINSULARES
}

\author{
Irene Sebastián Perdices y Bienvenido Morros Mestres \\ Universitata Autònoma de Barcelona \\ Bienvenido.Morros@uab.cat
}

La fábula de Ifis y Anaxárete no fue muy conocida en la Península Ibérica durante la Edad Media: Alfonso el Sabio, por ejemplo, no la recrea en su General Estoria, y los poetas castellanos de cancionero tampoco incluyen a ninguno de sus protagonistas en los muchos infiernos de amor que llegaron a componer, por más que se hallen entre los seguidores de Cupido en los Trionf (I, 2, I5I-I53) de Petrarca. Sólo Juan del Encina, al imitar a éste muy directamente, los recordó en su Triunfo de amor (vv. 4I7-4I8). En el Triunfo de las donas Juan Rodríguez del Padrón había aprovechado algún elemento de nuestra fábula para la historia de Aliso y Cardianar. Asimismo Diego de san Pedro, en la Cárcel de amor (I492), pone en boca de Leriano (antes de suicidarse éste) las mismas palabras que Ovidio había puesto en la de Ifis en idénticas circunstancias. Solo los traductores de una de las obras de John Gower difundieron la fábula con todas sus partes, pero sus versiones portuguesa y castellana apenas tuvieron resonancia en nuestra literatura. Esos traductores, como veremos en seguida, reprodujeron el error de su original, que curiosamente también presenta un poeta del Renacimiento. En las páginas que siguen propondremos una hipótesis para explicar esa coincidencia en el error (propiamente un error communis coniuctivus) en autores tan distantes en el tiempo y también en el espacio.

Valdrá la pena para empezar leer el verso de las Metamorfosis de Ovidio en que debió de haberse producido ese error. El verso pertenece al monólogo que pronuncia Ifis ante la casa de Anaxárete en el momento preciso en que lo está preparando todo para ahorcarse en su puerta:

Vincis, Anaxarete, neque erunt tibi taedia tandem

Ulla ferenda mei $[\ldots]^{2}$

I Así lo señala María Rosa Lida de Malkiel, I953, p. 328.

2 Usamos la edición de Bartolomé Segura Ramos, I983, vol. III, p. I57.

MEDIEVALIA I6 (2013), I33-I39

ISSN: O2II-3473 (paper), 20I4-84IO (digital) 
Vences, Anaxárete, y finalmente tú no tendrás que sufrir más enfados por mí [...].

El traductor castellano de la Confessio amantis de John Gower, Juan de Cuenca, utiliza la palabra "enojo" (en singular, no en plural) para trasladar el original taedia, en un parlamento en que el protagonista primero se dirige a la pareja Venus-Cupido y después a su amada. La fábula la aduce John Gower para ilustrar una de las modalidades del pecado de la pereza (tristeza o desesperación) al que ha dedicado el libro IV de su poema:

¡Oh tú, Cupido e Venus [...] pues otra melezina non puedo fallar por acabamiento de mi enojo, la muerte me será en lugar de melezina [...] Oh muy dolorida y amada señora, aquesta es la casa de tu padre donde tú moras e duermes en tu cama a plazer, e del mi enojo que yo tengo muy poco oyentes... ${ }^{3}$

Es raro que Juan de Cuenca (y en su defecto Roberto Paim, y también el propio John Gower) haya entendido mal la construcción del verbo esse más dativo de interés que usa Ovidio en esos dos versos (erunt taedia tibi; literalmente, 'serán los hastíos, molestias para ti'). Nos da la impresión de que el propio autor inglés ha empleado un manuscrito de las Metamorfosis — si es esa su fuente directaque contiene un error en esos versos: el cambio de tibi por mibi. En la edición crítica de la obra latina que manejamos, no aparece reflejado en ninguno de los testimonios que su autor ha usado, pero sí se recoge otro de ese mismo tipo, solo cinco versos después: donde Ovidio escribió tui los copistas llegaron a copiar tibi e incluso mihit. Estamos casi seguros de que en esa tradición que desemboca en Juan de Cuenca el verso de las Metamorfosis se había copiado con un claro error ("mihi" por "tibi”):

Vincis, Anaxarete, neque erunt mihi taedia tandem

Ulla ferenda mei...

Los versos se pueden traducir, como se traducen muchas de las oraciones latinas, con el verbo esse acompañado de dativo (el dativo pasa a ser el sujeto de la oración y el verbo copulativo se traduce por 'tener'): 'Vences, Anaxárete, y finalmente yo no tendré más molestias que sufrir por mí. En esa versión, es perfectamente lógico que el Ifis de Roberto Paim y Juan de Cuenca se refiera a su propio enojo (y no al de la amada). No hallamos otro modo de explicar tal confusión o cambio.

3 Usamos la edición paleográfica de Elena Alvar, 1990, pp. 377-378.

4 Así lo recoge Bartolomé Segura Ramos en el aparato crítico de su edición (1983), p. I57. 
Pero Juan de Cuenca se limita a traducir — a veces incluso muy literalmenteel texto portugués de Roberto Paim (es lo que hace con la palabra clave, también repetida dos veces en su modelo, noio, "enojo"), pero curiosamente conserva, como veremos a continuación, algún pequeño detalle del poema inglés:

Oo tu Cupido et tu Venus [...] E porem pois outra meezinha nom posso achar por acabamento de meu noio a mynha morte me stara em logo de saude. Oom mynha doorida et cara senhor, que aquy moras com teu padre et em tua cama dormes a teu prazer, do noio que eu agora hey muyto pouco sabes parte nem como tu et eu pollo presente somos desyguaaes 5 .

En principio, Roberto de Paim tiene como modelo inmediato pero también fundamental el poema de John Gower, quien emplea para la palabra clave dos formas distintas ("querele" y "desese"):

O thou Cupide, o thou Venus [...]

Thus for I se no medicine

To make an ende of mi querele,

My deth schal be in stede of hele [...]

$\mathrm{Ha}$, thou mi wofull ladi diere,

Which duellest with thi fader hiere

And slepest in thi bedd at ese,

Thou wost nothing of my desese (IV) ${ }^{6}$.

El poeta inglés, que también había usado la lengua francesa para otras obras suyas, traduce los taedia de Ovidio con una palabra ("querele") que en principio no pertenecía al mismo campo semántico. El sustantivo taedium, como hemos visto, podía tener distintos sentidos, desde el primero y más literal de 'hastío, cansancio' (en Ovidio es el de Anaxárete por ver todos los días a Ifis) al traslaticio de 'molestia' e incluso 'enfado'. La palabra "querele", por influencia del latín, equivalía a 'lamento, queja' o 'disputa', y en francés parece documentarse también como sinónimo de 'preocupación' y 'dolor', pero ninguna de estas acepciones se corresponde con las señaladas para taedium. Está claro que de haberse inspirado directamente en las Metamorfosis (pudo haberlo hecho a través de algún texto intermediario) hubo de manejar por fuerza una copia de

5 Los tres primeros libros de la traducción portuguesa han sido editados por M. Faccon, 2007, edición que citamos aquí en sus pp. 290-29I.

6 Manejamos la edición clásica de Gower a cargo de G. C. Macaulay, I90I, vol. 2, p. 397; y también la realizada por Russell A. Peck, 2003, p. 321.

7 Macaulay, en su glosario, recoge los siguientes sentidos: "cause, quarrel, enterprise": véase Gower, ed. Macaulay, I90I, vol. 3, p. 62I ab. 
esa obra con el error mibi taedia, porque eligió el pronombre de primera persona y no el de segunda. No cabe descartar que el poeta inglés buscara una palabra diferente a la de Ovidio, por considerarla más adecuada para reflejar el tipo de contrariedades a las que piensa poner fin el amante con su muerte. Al entender que Ifis no debía sentir ningún hastío de sí mismo, creyó oportuno atribuirle un sentimiento más acorde con su situación de amante desdeñoso. Al comprobar que el infortunado muchacho se pasaba todo el tiempo lamentándose ante la puerta de su amada, pensó que era más propio hacerle decir que con su muerte dejaría de lamentarse más.

No menos extraño es el modo en que Roberto de Paim decide traducir la palabra inglesa "querele", cuando para hacerlo busca no un sinónimo, sino otra palabra, noio, que parece llevarlo directamente a la fuente latina. Podría pensarse que el traductor portugués no sólo ha tenido delante para su tarea el poema inglés sino también el texto de Ovidio. No sabemos si lo hace de manera sistemática (para comprobarlo habría que estudiar cada palabra de su texto) o sólo muy ocasionalmente. Pero otros poetas, muy posteriores, que no pudieron haber leído ninguna de las dos traducciones peninsulares, eligen idéntica palabra (pero en plural) para traducir taedia: "enojo" y "enojos". Si dos autores (en principio por separado) coinciden en vulgarizar el mismo vocablo latino, dan a entender que un tercero, que también haga lo mismo por su cuenta y riesgo, lo hace porque no hallado una solución mejor y más precisa.

En L'Ameto, Boccaccio menciona nuestra fábula y también reproduce - eso sí, indirectamente - algunos de los versos que Ifis dirige a su amada. El texto del italiano es anterior al inglés de Gower, pero los dos podrían remontarse a una tradición de las Metamorfosis que contuviera el error que ya hemos señalado. Boccaccio utiliza el personaje de Caleone para narrar su propio enamoramiento de Fiammetta. Antes de hacerlo, refiere su encuentro con dos damas (Pampinea y Abrotonia) que se la acabarán mostrando después de escarnecerlo repetidas veces. Caleone, en un principio, logra algunos grados del amor con la segunda de estas damas (sobre todo, abrazos), quien acaba rechazándolo en seguida. El futuro amante de Fiammetta quiere reconquistar el amor de Abrotonia y, al no conseguirlo, se dirige a su habitación para buscar el modo de aliviar sus penas. Se equipara entonces a Ifis y a Biblis, y recuerda muy claramente uno de los versos que Ovidio pone en boca del primero:

Certo io estimo che'l dolore della impaziente Didone fosse minore che'l mio, quand'ella vide Enea dipartirsi [...] ma così dolente la mia camera ricercai; nella quale solo più volte l'angosce mie, come Ifi o Biblide, míseramente pensa' di finire8

8 Usamos la edición de E. Bianchi, C. Salinari y N. Sapegno, I952, pp. IOI9-IO2O. 
Caleone, al igual que Ifis, ha pensado en el suicidio como la solución más efectiva para terminar con su sufrimiento amoroso. Boccaccio traduce el plural taedia por l'angosce para atribuírsela a él mismo y no a Abrotonia, poniendo de manifiesto que sigue una versión de la obra ovidiana muy similar a la que ańos después acabará usando John Gower. Boccaccio, como es sabido, fue leído e imitado por Geoffrey Chaucer en los Canterbury Tales y en el Troilus and Criseida.

Diego de San Pedro, en la obra que le dio más fama, la Cárcel de amor (publicada en I492) recurrió a la fábula de Ifis y Anaxárete para la parte en que describe el suicidio y la muerte de su protagonista. Tras leer la carta en que Laureola le pide que no vuelva a escribirle, Leriano es consciente de que la ha perdido para siempre; sin esperanza, pensando ya en el suicidio, se acuesta feliz porque sabe que al morir prestará el último y más importante servicio de amor a su amada (desapareciendo, dejará de causarle más molestias):

Y desconfiado ya de ningún bien ni esperanza, aquexado de mortales males, no podiendo sostenerse ni sofrirse, uvo de venir a la cama, donde ni quiso comer ni bever ni ayudarse de cosa de las que sustentan la vida, llamándose siempre bienaventurado porque era venido a sazón de hazer servicios a Laureola quitándola de enojos9.

Es obvio que Diego de San Pedro ha utilizado una copia de las Metamorfosis sin el error que debió presentar el ejemplar que había manejado John Gower, y también Boccaccio. El cortesano de Enrique IV traduce, al igual que Roberto Paym y Juan de Cuenca, la palabra latina "taedia" por 'enojos": parece haber leído directamente ese pasaje de la obra de Ovidio.

Garcilaso de la Vega es otro de los autores que también interpreta "taedia" como "enojos", cuando en su Égloga II recrea, a través de Albanio y Camila, la fábula de Ifis y Anajárete. El toledano presenta a su pastor al borde de un precipicio, a punto de arrojarse al vacío, pronunciando (casi literalmente, y a veces duplicados e incluso triplicados) los mismos versos de Ovidio:

Heme entregado, heme aquí rendido,

He aquí que vences; toma los despojos

De un cuerpo miserable y afligido!

Yo porné fin del todo a mis enojos;

Ya no te ofenderá mi rostro triste,

Mi temerosa voz y húmidos ojos $(566-57 \mathrm{I})^{10}$.

9 Usamos la edición de C. Parrilla, I995, p. 64. Io Usamos la edición de B. Morros, 1995, p. I69. 
Garcilaso ha interpretado taedia de la misma manera que los autores anteriores (sólo pudo haber leído a Diego de San Pedro, pero a ninguno de los otros) y se los ha atribuido, igual que había hecho Juan de Cuenca y los autores a quienes éste traduce, a Albanio (y no a Camila). El Brocense, que era un lince, se dio cuenta de que el verso del toledano contenía un cambio importante con respecto a su modelo, y él atribuyó el cambio a un error de los editores que habían difundido la Égloga II. No contempló la posibilidad de que el error no fuera de los editores del toledano, sino de los del poeta latino.

Ante los ejemplos que hemos aducido en nuestro trabajo, conviene que lo terminemos planteando un dilema de alta ecdótica. Los editores de Garcilaso tienden a seguir al Brocense al emendar el verso del toledano que hemos citado arriba. Pero, de atestiguarse un error en el verso correspondiente de Ovidio, ¿qué deberá hacer el editor de la égloga? ¿Subsanar el verso en cuestión, como sugiere el Brocense, o dejarlo con el error porque, siéndolo, es error en definitiva del propio autor que ha empleado una edición o manuscrito con la lectura erunt mihi taedia? Es un dilema al que debe hacer frente cualquier editor que pretenda no reproducir un texto inexistente (quizá "Yo porné fin del todo a tus enojos" es un verso que no existió nunca) sino el más cercano a la voluntad de su autor (en este caso "Yo porné fin del todo a mis enojos"). Pero tampoco tenemos la certeza absoluta (casi nunca la tenemos en crítica textual) de que el toledano hubiera recreado el verso de Ovidio con ese error. Sin esa certeza lo más razonable es la prudencia y la adopción de un criterio conservador. Ante la duda es mejor dejar el verso con la lectura del testimonio o testimonios que la hayan transmitido.

\section{BIBLIOGRAFÍA}

Boccaccio, Giovanni, 1952, Decameron. Filocolo. Ameto. Fiammetta, ed. E. Bianchi, C. Salinari y N. Sapegno, Milán-Nápoles.

Faccon, M., 2007: La fortuna de la "Confessio amantis" en la peninsula ibérica: estudio comparativo de las traducciones y edición del ms. Madrid, Real Biblioteca, $I I-3088$, tesis doctoral dirigida por M. J. Lacarra y R. Brasegan, Zaragoza.

Garcilaso de la Vega, I995: Obra poética y textos en prosa, ed. B. Morros, Barcelona. Gower, J., I90I: The Complete Works of John Gower. Edited from the Manuscripts with Introductions, Notes, and Glossaries, ed. G. Macaulay, Oxford.

—, 2003: Confessio Amantis, ed. de R. A. Peck, Michigan.

- I990: Confesión del Amante, Tradución de Juan de Cuenca (Siglo XV), ed. paleográfica E. Alvar, prólogo M. Alvar, Madrid. 
Lida de Malkiel, M. R., 1953: "Juan Rodríguez del Padrón: vida y obras", Nueva Revista de Filología Hispánica, VI, p. 328.

Ovidio, 1983: Metamórfosis, vol. III, ed. B. Segura Ramos, trad. A. Ruiz de Elvira, Madrid.

San Pedro, Diego de, 1995: Cárcel de Amor, ed. C. Parrilla, Barcelona. 
